\title{
Higher brain functions served by the lowly rodent primary visual cortex
}

\author{
Jeffrey P. Gavornik and Mark F. Bear
}

Howard Hughes Medical Institute, The Picower Institute for Learning and Memory, Department of Brain and Cognitive Sciences, Massachusetts Institute of Technology, Cambridge, Massachusetts 02139, USA

\begin{abstract}
It has been more than 50 years since the first description of ocular dominance plasticity-the profound modification of primary visual cortex (V1) following temporary monocular deprivation. This discovery immediately attracted the intense interest of neurobiologists focused on the general question of how experience and deprivation modify the brain as a potential substrate for learning and memory. The pace of discovery has quickened considerably in recent years as mice have become the preferred species to study visual cortical plasticity, and new studies have overturned the dogma that primary sensory cortex is immutable after a developmental critical period. Recent work has shown that, in addition to ocular dominance plasticity, adult visual cortex exhibits several forms of response modification previously considered the exclusive province of higher cortical areas. These "higher brain functions" include neural reports of stimulus familiarity, reward-timing prediction, and spatiotemporal sequence learning. Primary visual cortex can no longer be viewed as a simple visual feature detector with static properties determined during early development. Rodent V1 is a rich and dynamic cortical area in which functions normally associated only with "higher" brain regions can be studied at the mechanistic level.
\end{abstract}

\section{Ocular dominance plasticity and the critical period concept}

Visual information is processed by a hierarchy of cortical processing regions that extract increasingly abstract features from images formed on the retinas (Hubel and Wiesel 1968; Felleman and Van Essen 1991; Riesenhuber and Poggio 1999; DiCarlo et al. 2012). Conscious perception somehow emerges from the distributed neural representations of visual information as they cascade through the brain. This basic conceptual framework, which has dominated the field for decades, relies in part on the assumption that primary visual cortex (V1) is an immutable feature detector with properties established during a well-defined "critical period" of developmental plasticity. The experimental roots of this model are based on Hubel and Wiesel's pioneering work on the ascending visual pathway in cats. In a series of studies, made possible by the development of tungsten microelectrodes for in vivo recording (Hubel 1957), they established several important features of V1 that profoundly shaped how we understand the mechanistic basis of visual processing and experience-dependent cortical plasticity (Hubel and Wiesel 1962; Wiesel and Hubel 1963a,b, 1965; Hubel et al. 1976).

First, they found that projections from the two eyes, which remain segregated in the LGN, converge on single neurons in V1 (Hubel and Wiesel 1962). These binocularly responsive neurons have receptive fields in the two eyes with matched retinotopy and stimulus preference. That is, a stimulus (usually an oriented bar of light) found to elicit activity when presented to a specific location on the retina of one eye would also elicit activity when presented to the same retinal location on the other eye. They also found that neighboring neurons share similar orientation tuning preferences (Hubel et al. 1976). These observations implied a degree of synaptic specificity that seemed difficult, if not impossible, to accomplish through genetic coding alone, and suggested

\section{Corresponding author: mbear@mit.edu}

Article is online at http://www.learnmem.org/cgi/doi/10.1101/Im.034355.114. an important role for early sensory experience in fine-tuning cortical connectivity.

Second, they found that not all neurons are equally responsive to both eyes; some neurons respond relatively robustly to activity in one eye while others respond robustly to the other eye. They termed this property "ocular dominance" (OD). Importantly, the distribution of OD values depends on visual experience (Wiesel and Hubel 1963a,b, 1965). This was demonstrated by subjecting kittens to a period of monocular deprivation (MD), i.e., the temporary closing of one eyelid. Following MD most neurons in V1, which normally respond to stimulation from either eye, can be activated only by the eye that remained open. Despite the fact that the closed eye and optic projections remain intact, the visual cortex is no longer able to "see" the activity that it generated. This finding has been interpreted to show that synaptic connectivity is established via a competitive learning process, and OD plasticity quickly became the premier model system to study how activity drives the biophysical processes thought to accompany learning and memory.

Third, they found the effects of visual deprivation decrease with age (Hubel and Wiesel 1970). In kittens, the effects of MD taper off at $\sim 3$ mo of age. Before this point, restoration of normal vision following MD can cause lost function and cortical responsiveness to recover. After this, however, normal vision results in minimal recovery (Wiesel and Hubel 1965). This finding led to the important and influential idea that experience-dependent modifications to sensory cortex are restricted to a developmental window analogous to the critical period of early embryogenesis during which cell fate is irreversibly determined by local cellular interactions (Spemann and Mangold 2001). As a result, it is difficult or impossible for visual experience to change cortical

2014 Gavornik and Bear This article is distributed exclusively by Cold Spring Harbor Laboratory Press for the first 12 months after the full-issue publication date (see http://learnmem.cshlp.org/site/misc/terms.xhtml). After 12 months, it is available under a Creative Commons License (AttributionNonCommercial 4.0 International), as described at http://creativecommons. org/licenses/by-nc/4.0/. 
connectivity patterns after this window closes except in the dramatic case of neural damage (Kaas et al. 1990; Keck et al. 2008).

\section{Rodent V1 reports stimulus familiarity}

Most of the early studies investigating visual physiology and developmental plasticity were performed in cats or monkeys. Subsequent work has shown that rodent $\mathrm{V} 1$ shares many of the features from these animals including robust OD plasticity (Domenici et al. 1992; Fagiolini et al. 1994; Gordon and Stryker 1996; Sawtell et al. 2003). The mouse, in particular, has emerged as a model system in which the modern genetic toolkit can be leveraged to probe the mechanistic basis of experience-dependent developmental plasticity, both in wild-type mice and in animals carrying mutations that cause human disease. Like cats and monkeys, mouse V1 contains a topographic mapping of visual space (Wagor et al. 1980; Wang and Burkhalter 2007; Smith and Hausser 2010), has orientation-selective simple and complex cells (Ohki et al. 2005; Niell and Stryker 2008), and synaptic specificity at the level of single neurons (Ko et al. 2011). Because orientation-selective neurons are intermingled with a "salt-and-pepper" organization (Ohki et al. 2005), it is relatively easy to longitudinally sample the activity of neurons with a wide variety of response properties using chronically implanted recording electrodes, and visually evoked potentials (VEPs, visual stimulus-locked fluctuations in the local cortical field potential) can be used to assess both visual function and OD plasticity in awake animals (Huang et al. 1999; Porciatti et al. 1999; Sawtell et al. 2003; Frenkel and Bear 2004). One of the first surprises that emerged from studies of OD plasticity in mice using chronic recording methods is that it can persist well into adulthood (Sawtell et al. 2003; Hofer et al. 2006; Matthies et al. 2013).

Our laboratory also noticed that the trough-to-peak magnitude of VEPs, evoked by a high-contrast phase-reversing grating and recorded in awake animals using electrodes implanted in binocular V1 Layer 4 (see Fig. 1), increased steadily over recording days until they reached a plateau around the fourth or fifth day of stimulus presentation (Sawtell et al. 2003). The initial assumption was that "electrode drift", possibly due to gliosis or some other compensatory response to electrode implantation, was responsible for this confounding instability. On closer examination, however, this potentiation was found to be highly specific for the spatial content of the visual stimulus used to elicit VEPs. As shown in Figure 1B, the potentiated response to a phase-reversing sinusoidal grating is lost when the same grating is rotated by $45^{\circ}$. In other words, baseline VEP magnitude is stable as long as a new orientation is used in each recording session. This effect, termed stimulusselective response potentiation (SRP), depends on mechanisms shared with NMDA receptor-dependent long-term potentiation (LTP) and reflects the neural coding of stimulus familiarity (Frenkel et al. 2006; Cooke and Bear 2010).

\section{Rodent V1 reports reward timing}

The SRP phenomenon is fascinating in its own right and is potentially a powerful tool to study visual recognition memory and the pathophysiology of psychiatric disease (Cooke and Bear 2012). For the purposes of this review, however, there are two particularly salient observations. First, visual experience robustly and directly shapes the physiological response properties of V1 neurons in adult mice. Second, as shown using a variety of experimental approaches (for review, see Cooke and Bear 2014), changes in the physiological response properties are largely based on plasticity occurring in V1 and not feedback from higher cortical regions. These findings cast doubt on long-accepted ideas about adult pri-
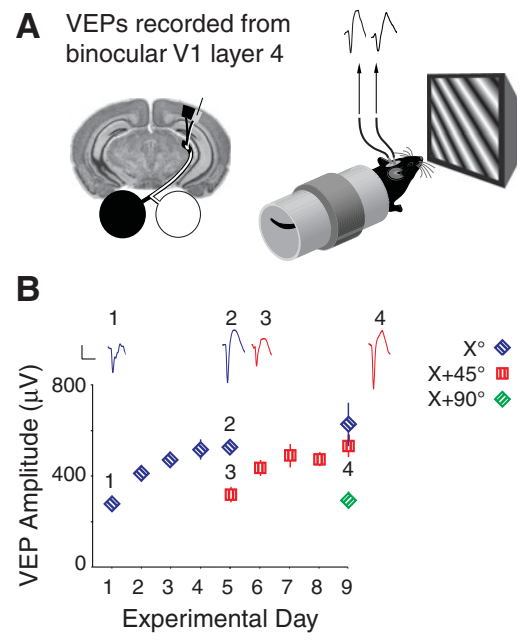

Figure 1. Stimulus-specific response potentiation (SRP). (A) Visualevoked potentials (VEPs) are recorded from both hemispheres of headfixed, awake, male C57BL/ 6 mice and driven by full-field, high-contrast, phase-reversing sinusoidal grating stimuli. Electrodes are positioned in Layer 4 of the binocular region of V1. (B) The trough-to-peak magnitude of average VEPs evoked by a stimulus oriented at $X^{\circ}$ (blue) potentiates over multiple viewings (Days 1-5). This potentiation is selective for the specific stimulus, demonstrated by the fact that VEPs evoked by novel orientations (on Days 5 and 9 , offset in $45^{\circ}$ increments from $X^{\circ}$, red and green) have magnitudes equivalent to the Day 1 magnitude for $X^{\circ}$ and also potentiate across repeated presentations. (Insets) Representative VEP waveforms at indicated time points (scale bars, $100 \mu \mathrm{V} \times 50 \mathrm{msec}$ ). (All data adapted from Frenkel et al. 2006).

mary visual cortex. The notion that $\mathrm{V} 1$ function is locked down after development, implied by the critical period concept, comports well with its presumptive function as a simple feature detector. SRP and other forms of perceptual learning (Gilbert and Li 2012), however, suggest that V1 may be able to learn a range of capabilities beyond those characterized for the case of normal vision.

Our laboratory set out to address this possibility directly by pairing visual stimulation with an ethologically salient reward. In a series of experiments (Fig. 2A,B; Shuler and Bear 2006), goggles were used to deliver full-field flashes to either the left or the right eye of water-deprived rats. This visual stimulus served as a cue to begin licking a dispenser which delivered a water reward following fixed temporal intervals (measured in number of licks). The duration of these intervals depended on which eye had been stimulated ( $n$ licks for the left eye, $2 n$ for the right). In early trials, as expected, visual responses recorded in V1 lasted only as long as the flash $(400 \mathrm{msec})$. After repeated presentations over several days, however, the same brief stimuli evoked responses that persisted until the time of reward delivery, even on trials during which reward was not delivered. In essence, neurons in V1 had learned to predict the time of anticipated rewards by responding to visual inputs with dynamics reflecting the stimulus-reward intervals established during the training period and not those of the visual stimuli actually evoking their activity.

These results challenge the traditional view of $\mathrm{V} 1$ by showing that activity in V1 neurons can both reflect past associations between sensory stimuli and gustatory rewards and can also explicitly represent neural instantiations of learned temporal intervals. These functions are normally ascribed to "higher processing" regions of the cortex and associated subcortical areas (Fuster and Jervey 1981; Schultz et al. 1997; Komura et al. 2001; Egorov et al. 2002; Leon and Shadlen 2003; Watanabe and Funahashi 2004), but not primary sensory areas. Models of the presumptive 
A
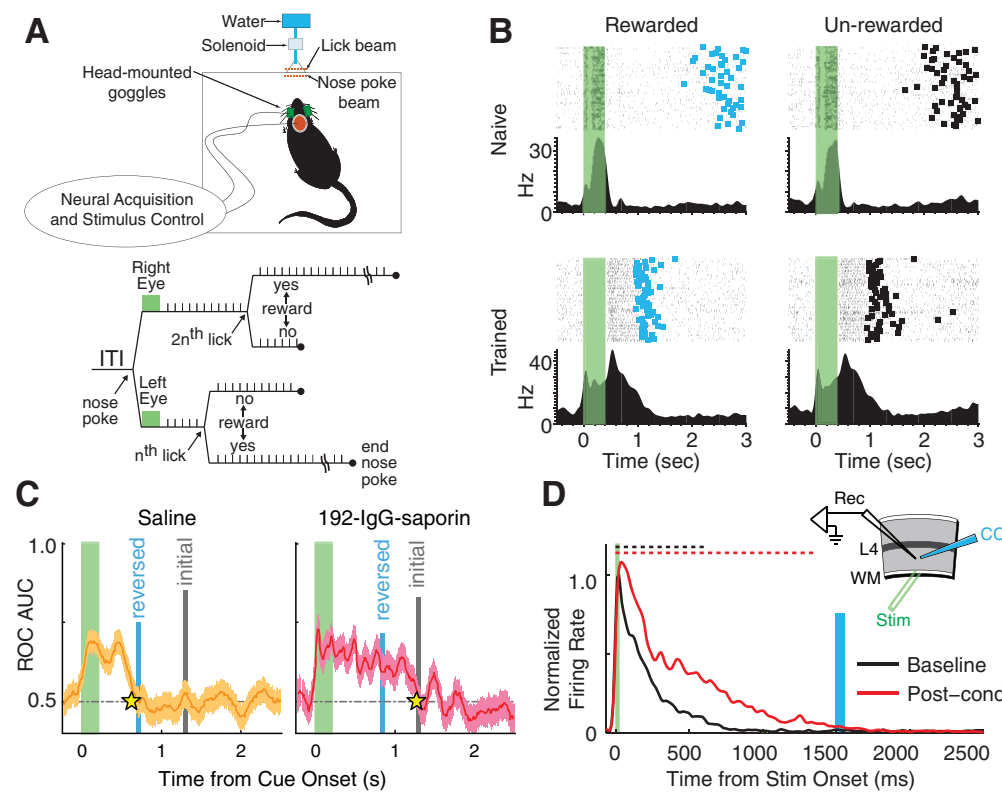

D

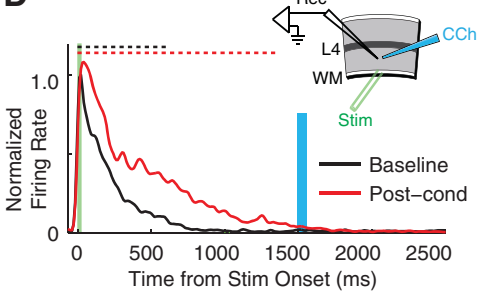

Figure 2. Reward-modulated interval timing learned in V1. (A) Schematic of the in vivo experimental design and trial flow from Shuler and Bear (2006). Light flashes were delivered to either the left or right eye following nose pokes and the number of licks (i.e., time) required before water-reward delivery depended on which eye was stimulated. (B) In naïve animals (top row), the duration of evoked responses (raster plots over PSTH) matched the stimulus duration ( $400 \mathrm{msec}$, indicated by green rectangle). After training, evoked activity persisted until the time of reward delivery (blue rectangles, left column), even on unrewarded trials (right column, time when reward would have been given indicated by thick black rectangles). (C) In Chubykin et al. (2013), rats were trained with a long interval between stimulus and reward and then treated with local injections of either IgG-saporin (to lesion cholinergic projections) or saline (control) in V1. The rats were then retrained with a short interval. Whereas the control animals were able to learn the new shortened interval, those with lesions continue to report the original timing. In both panels, the gray and blue vertical lines show the average reward-delivery times before and after lesioning, the star indicates the average reported time post-lesion, and neural interval reports are determined by a receiver operating characteristic (ROC) threshold crossing (see Chubykin et al. 2013 for details). (D) Repeated delivery of carbachol (a cholinergic agonist) after electric white matter stimulation produced a period of evoked spiking in mouse V1 slices that matched the interval between the two stimuli (electrical stimulation at time 0, CCh delivery indicated by blue rectangle, dashed lines show average scored response durations). (Data adapted from Shuler and Bear 2006 $[A, B]$, and Chubykin et al. $2013[C, D]$.

V1 visual processing algorithm provide no explanation for why this temporal information should be available in V1 making it difficult to speculate on its functional consequences (although theoretical arguments against the standard feed-forward processing model have been made, e.g., Hochstein and Ahissar 2002). The observed neural activity, however, must result either from activity that emerges in the earliest visual processing stages or be fed-back from higher cortical areas (in which case the activity reported in $\mathrm{V} 1$ is a low-level reflection of high-order processes). Accumulating evidence puts the mechanism for learning reward-timing squarely within V1.

The first indication that the relevant plasticity occurs locally in V1 came from the fact that learned intervals did not transfer between the two eyes. There is no evidence that monocular segregation persists beyond V1, as would be required for any higher learning locus to pass monocularly segregated temporal representations back into $\mathrm{V} 1$, and parsimony alone argues that the relative simplicity of a local processing circuit is the most likely explanation. These findings might be explained if a modulatory input into V1 signifying reward-permitted long-term potentiation of recently active synapses within the local circuit.

This theoretical possibility was explored computationally in a series of papers that showed how reward-modulated plasticity of excitatory synapses in the V1 circuit could produce temporal rep- resentations with the same basic features seen experimentally (Gavornik et al. 2009; Gavornik and Shouval 2011; Shouval et al. 2013, 2014). This learning model posits that a globally available reward signal allows Hebbian-type associations, transiently encoded by the molecular precursors of LTP termed "proto-weights," to be expressed as permanent synaptic modifications, and that ongoing activity in the network quashes additional potentiation once evoked activity correctly predicts the time of reward delivery. In addition to making specific testable predictions about how neural tuning curves and recurrent excitation can influence the dynamics of evoked responses, these models also demonstrate that the circuits in V1 constitute a sufficient substrate to express and learn temporal intervals. Although these computational works do support the idea temporal coding can occur in V1, they cannot identify the relevant biology actually used by the brain to do so. For instance, what is the "reward signal" required to encode time in V1?

Dopamine, which is often characterized as a modulatory reward signal (Schultz 1998), is an obvious candidate. Dopamine projections to $\mathrm{V} 1$ are relatively sparse (Papadopoulos et al. 1989), however, whereas cholinergic projections from the basal forebrain are robust and are known to be responsive to thirst satiation (Sullivan et al. 2003). The cholinergic system is also well-documented to play an important role in learning and memory (Hasselmo 2006), and subsequent experiments designed to test the theoretical predictions described above showed definitively that cholinergic activity is necessary to learn interval timing in V1 (Chubykin et al. 2013). First, targeted delivery of the immunotoxin 192-IgG-saporin was used to selectively lesion cholinergic projections to V1 in rats. In these experiments, $\mathrm{V} 1$ neurons were able to report intervals established before the lesion, but they were unable to update their activity to reflect new timings after the cholinergic projections were lost (Fig. 2C). Neurons in control animals, in contrast, were able to learn new intervals following sham injections. In addition to demonstrating the necessary role of the cholinergic system, these experiments are also highly suggestive that temporal interval coding occurs locally in V1 since the saporin was delivered only to V1.

Parallel efforts in slices of visual cortex, isolated from the rest of the brain in vitro, show that cholinergic modulation of activity in V1 is also sufficient to code temporal intervals. In these experiments, electrical white matter stimulation in cortical slices including area V1 was followed by brief application of carbachol (a cholinergic agonist) after a fixed interval. As was the case in vivo, extracellular recordings showed that Layer 5 neurons in naïve slices respond transiently to electrical stimulation with dynamics reflecting the stimulus duration. After the pairing protocol, evoked response durations accurately predicted the interval between electrical stimulation and carbachol delivery established during the training period (Fig. 2D). In addition to corroborating 
cholinergic involvement in this form of learning, this result also demonstrates definitively that plasticity within isolated V1 circuitry can support temporal interval coding as predicted by the models.

\section{Rodent V1 reports familiar spatiotemporal sequences}

The abilities to recognize patterns in topographic mappings and to process temporal information are critical features of nervous system function (Patel et al. 2014). As we have seen, V1 can encode both spatial and associative-temporal aspects of visual experience. But can it also encode specific spatiotemporal experience? poral sequence of oriented gratings over a 4 -d training period (Fig. 3A; Gavornik and Bear 2014). The sequence-evoked response magnitude increased over training days in a manner similar to that described above for SRP. If, as was the case with SRP, this potentiation represented coding only of the training sequence's spatial content, then response magnitudes should be largely independent of the order and timing with which the sequence elements are presented. Instead, as shown in Figure 3B-D, the evoked responses were largest when the sequence elements were presented with the order and timing established during the training period; when the same visual elements were presented with a novel order We tested this by repeatedly presenting mice with a specific tem-

or timing, evoked responses were smaller. This demonstrates that neurons in V1 can learn to recognize both the ordinal and temporal content of spatiotemporal sequences.

The ability to make accurate predictions and react before something happens confers a huge evolutionary advantage. How the brain learns to extract and recognize relevant information from temporally continuous streams of noisy sensory data, and to use this information as the basis for predictions, remains a fundamental mystery. The results described above could be explained if V1 learned to expect what it would see when. Indeed, our experiments indicate that V1 can actively predict expected visual stimuli with a high degree of temporal precision. This was demonstrated by removing a sequence element and replacing it with a gray screen. As shown in Figure 3E, the electrical current source/sink pattern evoked by an expected, but unshown, spatiotemporal sequence element is almost identical to that evoked when the stimulus is actually shown. That is, V1 is active when it expects to see a stimulus even if the stimulus is not actually shown.

As before, these findings show evidence of presumptive "higher" cortical functions that are at odds with dogma. And, as before, the possibility exists that the V1 physiology reflects learning and computations occurring elsewhere in the brain. Evidence suggests, however, that the synaptic bases of the memories constituting spatiotemporal representations also exist locally within V1. This evidence consists of monocularly separated response potentiation (i.e., learning associated with a sequence viewed through one eye does not transfer to the other eye) and the ability of pharmacological agents delivered locally to V1 to block sequence potentiation. Specifically, sequence acquisition was prevented by antagonizing muscarinic acetylcholine receptors (using scopolamine) but, surprisingly, blocking the NMDA receptors (via CPP) had no effect.

A series of contemporaneous studies also showed that V1 neurons can replay activity sequences associated with visual experience in the rat (Xu et al. 2012). In these experiments, repeated presentations of a moving spot during a single recording session created a sequential representation of the evoked activity pattern along the spot's retinotopic trajectory. The quality of these representations, replay of which could be cued via brief flashes delivered at the stimulus trajectory starting point, depended on cortical state. In contrast to our experiments, these sequential representations were blocked by local delivery of the NMDAR antagonist APV and the speed of replay was largely independent of conditioning motion speed.

Figure 3. Learned spatiotemporal sequence representations in V1. (A) Four-element sequences with fixed timing ( $150 \mathrm{msec}$ per element followed by $1.5 \mathrm{sec}$ of gray screen) were shown to head-fixed male C57BL/ 6 mice repeatedly over $5 \mathrm{~d}$. $(B, C)$ The average sequence-evoked response (recorded in Layer 4) potentiated over days. On the fifth day, evoked field potentials were larger when the sequence elements were presented with the trained order and timing $(A B C D$, blue, triangles indicate the onset of each sequence element) than when they were reversed (DCBA, red) or slowed down $\left(A B C D_{300}\right.$, green, subscript indicates that each element is on screen for $300 \mathrm{msec}$ ). (D) Extracellular recordings show that the trained sequence $A B C D$ elicits more spiking than the reversed sequence $D C B A$ (color-coded spike rasters over PSTHs, dashed black lines show element onset times). ( $E$ ) Current source density analysis of laminar field recordings (16 electrodes spaced every $50 \mu \mathrm{m}$ from surface to white matter) show that the characteristic source-sink activation pattern evoked across the cortical layers by the sequence $A B C D$ persists even when element $B$ is not shown (A_CD, second element replaced with a gray screen, predictive response at the time that a stimulus was expected to be seen is highlighted with a green oval). (All data adapted from Gavornik and Bear 2014.)

\section{Plasticity in V1 may provide a window onto "canonical" functions of neocortex}

So what are the implications of these it is too early to say. V1 plasticity provides a possible substrate for various studies? From the perspective of vision, 
forms of perceptual learning, a process by which experience modifies visual detection thresholds (Gilbert and Li 2012). SRP, in particular, shares many of the hallmark features of perceptual learning (Cooke and Bear 2014), and recent work has shown that modulation associated with attention and locomotion can change behaviorally assayed processing capabilities of V1 in the mouse (Ayaz et al. 2013; Pinto et al. 2013; Fu et al. 2014). Thus, physiological changes in V1 can potentially result in a materially altered visual experience.

Unanswered questions of impact on vision aside, these findings of higher order plasticity in early visual cortex support the idea that there exists some common set of algorithmic primitives responsible for learning and processing information in all areas of the neocortex. Regionally specific functional differences, in this framework, are more the consequence of anatomically determined input patterns than specialized plasticity mechanisms or intracortical circuits. That is, visual cortex is visual cortex mainly because it receives projections from the retina. If it were to receive projections from the cochlea, for example, it would acquire the properties of auditory cortex. The logical extreme of this idea is the (somewhat polarizing) argument that vision is entirely empirical (Purves and Lotto 2011).

The hypothesis of "canonical" neocortical function is one of the most enduring in neuroscience, going back at least to the time of Cajal (1899) who commented that the grossly homogeneous six-layer neocortical structure might imply a common organizational plan. This idea has subsequently been proposed as a formal framework to understand cortical function (Creutzfeldt 1977; Mountcastle 1978; Douglas et al. 1989) and has been influential in shaping how many think about the brain. Recent anatomical analysis, using modern 3D reconstruction techniques, adds quantitative heft to earlier qualitative observations by showing that stereotypic stochastic connectivity provides a sufficient basis to create locally emergent functional specificity in cortical microcircuits (Hill et al. 2012). There is also functional evidence to support this idea. Notable in the context of the thought experiment described above, barrel-like anatomical patterning can be created in cortical tissue transplanted from V1 to S1 (Schlaggar and O'Leary 1991), and auditory cortex can assume properties of the visual cortex if retinal ganglion cell projections are rerouted to the medial geniculate nucleus of the thalamus (for review, see Newton and Sur 2005). Similarly, plasticity occurring in the context of Braille learning causes nominally visual areas to acquire the ability to process tactile information in blind people (Hamilton and Pascual-Leone 1998). The tentative success of sensory substitution systems, wherein artificial receptors are used to compensate for sensory loss by stimulating a remaining sense (Bach-yRita and Kercel 2003), also demonstrates the remarkable degree to which adult brains can rewire themselves to make sense of modality-specific stimulus patterns using brain regions that are in no way specialized for the task.

A growing body of evidence shows that other primary sensory areas share many of the properties described in V1. For example, the interval timing work follows earlier findings that the response properties of S1 neurons change according to whether whisker stimulation occurs in the context of passive or active tactile stimulation (Krupa et al. 2004). Context- and experiencedependent modifications of the auditory cortex have been particularly well characterized (Weinberger 2004, 2011), the olfactory cortex can acquire associative threat representations (Li 2014), and NMDA receptor-dependent associative learning even occurs within the primary motor cortex (Hasan et al. 2013). Recent results showing that rodents can volitionally generate specific neural activity patterns in S1 in order to receive reward (Clancy et al. 2014) further support the idea that primary sensory areas are capable of more than simple feature extraction within their specific modality and can play an active role in behaviorally relevant cortical processing.

Although this review is focused on work performed in rodents, there are tantalizing clues that similar processes may also be at play in humans and nonhuman primates. First, the performance gains associated with visual perceptual learning involve plasticity-modulated physiological changes in V1 (Schoups et al. 2001; Watanabe et al. 2002; Fahle 2004; Pourtois et al. 2008; Bao et al. 2010; Vogels 2010; Sale et al. 2011; Jehee et al. 2012) and are increased by cholinergic enhancement (Rokem and Silver 2013). Second, temporal association and sequential motion enhances familiar object recognition and representation (Stone 1998, 1999; Wallis 2002; Newell et al. 2004; Vuong and Tarr 2004; Cox et al. 2005; Balas and Sinha 2008, 2009; Li and DiCarlo 2008), showing that the primate visual system learns to use both spatial and temporal information. Third, human V1 responses are modulated by prior reward history (Serences 2008; Stanisor et al. 2013) and code expected reward value (Thomas et al. 2013). Fourth, predicted motion modulates the response of V1 neurons (Guo et al. 2007; Alink et al. 2010) and can result in perceptual illusions (Muckli et al. 2005; Seitz et al. 2005).

Despite the conceptual simplicity implied by the notion of a canonical neocortical circuit, no one really expects the cortical algorithms to be simple. As Cajal (1906) noted while accepting the Nobel Prize, nature is decidedly unimpressed by our desire for simplicity. That being said, the anatomical and functional evidence is sufficiently compelling to support the optimistic notion that we can formulate models of canonical function sufficiently accurate to provide biological insight. One influential class of models attempting this feat is based on the observations that intracortical connections provide the majority of excitatory drive to cortical neurons and are roughly balanced by inhibition (Douglas et al. 1989; Douglas and Martin 2004, 2007). In these models, feedforward inputs from the sensory epithelia do not drive activity so much as they allow the cortex to select a contextually appropriate activation pattern using stereotypical laminar microcircuits consisting of recurrent excitation and inhibition. These models fit well (Bastos et al. 2012) into another popular theoretical framework where the canonical function of cortex is a form of inference based prediction (Rao and Ballard 1997, 1999; Lee and Mumford 2003; Spratling 2010; Tavazoie 2013), although we note that our own finding that familiar spatiotemporal sequences evoke larger responses than unexpected sequences seems to be at odds with predictive coding models (Friston 2005; Wacongne et al. 2012). It should also be noted that purely feed-forward transformations seem best suited to account for rapid object categorization (DiCarlo et al. 2012) and active research continues on classically themed hierarchical models (e.g., Serre et al. 2007). Other models of canonical function have also been proposed, although it is less clear how they relate to our findings in visual cortex (e.g., Kouh and Poggio 2008; Carandini and Heeger 2012; Wang 2013). Ongoing efforts to use the concept of a canonical function to build neuroprosthetics (Casanova 2013) or artificially intelligent machines (e.g., Numenta (Hawkins and Blakeslee 2004), Google's "cat detector" (Le 2013), IBM's Watson) further attest to the seductive appeal of this hypothesis as a viable conceptual basis to understand the brain.

In conclusion, we believe that the experiments summarized in this review provide compelling evidence that the model of V1 as a simple feature detector provides an incomplete description of its full computational capabilities. It is clear that feed-forward processing plays an important role in vision, and the human disorder of amblyopia testifies powerfully to the functional reality of a critical period that determines when and how visual experience can modify the brain. However, it is increasingly apparent that primary visual cortex maintains a remarkable degree of plasticity 
that persists well beyond the OD critical period and supports functions not historically ascribed to V1. Accordingly, we believe that $\mathrm{V} 1$ is a viable model system to probe the mechanistic basis of learned higher order cortical functions and spatiotemporal memory storage in an accessible brain region.

\section{Acknowledgments}

This work was supported by the Howard Hughes Medical Institute, The Picower Institute Innovation Fund, the National Eye Institute (RO1 EY023037), and the National Institute of Mental Health (K99 MH099654). We thank Drs. Arnold Heynen and Sam Cooke for helpful comments on the manuscript, and Suzanne Meagher for administrative support.

\section{References}

Alink A, Schwiedrzik CM, Kohler A, Singer W, Muckli L. 2010. Stimulus predictability reduces responses in primary visual cortex. J Neurosci 30: 2960-2966.

Ayaz A, Saleem AB, Scholvinck ML, Carandini M. 2013. Locomotion controls spatial integration in mouse visual cortex. Curr Biol 23: 890-894.

Bach-y-Rita P, Kercel SW. 2003. Sensory substitution and the human-machine interface. Trends Cogn Sci 7: 541-546.

Balas B, Sinha P. 2008. Observing object motion induces increased generalization and sensitivity. Perception 37: 1160-1174.

Balas BJ, Sinha P. 2009. The role of sequence order in determining view canonicality for novel wire-frame objects. Atten Percept Psychophys 71: $712-723$.

Bao M, Yang L, Rios C, He B, Engel SA. 2010. Perceptual learning increases the strength of the earliest signals in visual cortex. J Neurosci 30: 15080-15084.

Bastos AM, Usrey WM, Adams RA, Mangun GR, Fries P, Friston KJ. 2012. Canonical microcircuits for predictive coding. Neuron 76: 695-711.

Cajal SR. 1899. Comparative study of the sensory areas of the human cortex. In Clark University, 1889-1899: decennial celebration (ed. Story WE), pp. 311-382. Clark University Press, Worcestor, MA.

Cajal SR. 1906. Santiago Ramon y Cajal - Nobel lecture: the Structure and connexions of neurons. Vol. 2014. Nobel Media AB 2013, Nobelprize.org.

Carandini M, Heeger DJ. 2012. Normalization as a canonical neural computation. Nat Rev Neurosci 13: 51-62.

Casanova MF. 2013. Canonical circuits of the cerebral cortex as enablers of neuroprosthetics. Front Syst Neurosci 7: 77.

Chubykin AA, Roach EB, Bear MF, Shuler MG. 2013. A cholinergic mechanism for reward timing within primary visual cortex. Neuron 77: $723-735$.

Clancy KB, Koralek AC, Costa RM, Feldman DE, Carmena JM. 2014. Volitional modulation of optically recorded calcium signals during neuroprosthetic learning. Nat Neurosci 17: 807-809.

Cooke SF, Bear MF. 2010. Visual experience induces long-term potentiation in the primary visual cortex. J Neurosci 30: 16304-16313.

Cooke SF, Bear MF. 2012. Stimulus-selective response plasticity in the visual cortex: an assay for the assessment of pathophysiology and treatment of cognitive impairment associated with psychiatric disorders. Biol Psychiatry 71: 487-495.

Cooke SF, Bear MF. 2014. How the mechanisms of long-term synaptic potentiation and depression serve experience-dependent plasticity in primary visual cortex. Philos Trans R Soc Lond B Biol Sci 369: 20130284.

Cox DD, Meier P, Oertelt N, DiCarlo JJ. 2005. 'Breaking' position-invariant object recognition. Nat Neurosci 8: 1145-1147.

Creutzfeldt OD. 1977. Generality of the functional structure of the neocortex. Naturwissenschaften 64: 507-517.

DiCarlo JJ, Zoccolan D, Rust NC. 2012. How does the brain solve visual object recognition? Neuron 73: 415-434.

Domenici L, Parisi V, Maffei L. 1992. Exogenous supply of nerve growth factor prevents the effects of strabismus in the rat. Neuroscience 51: $19-24$.

Douglas RJ, Martin KA. 2004. Neuronal circuits of the neocortex. Annu Rev Neurosci 27: 419-451.

Douglas RJ, Martin KA. 2007. Mapping the matrix: the ways of neocortex. Neuron 56: 226-238.

Douglas RJ, Martin KAC, Whitteridge D. 1989. A canonical microcircuit for neocortex. Neural Comput 1: 480-488.

Egorov AV, Hamam BN, Fransen E, Hasselmo ME, Alonso AA. 2002. Graded persistent activity in entorhinal cortex neurons. Nature 420: 173-178.

Fagiolini M, Pizzorusso T, Berardi N, Domenici L, Maffei L. 1994. Functional postnatal development of the rat primary visual cortex and the role of visual experience: dark rearing and monocular deprivation. Vision Res 34: 709-720.

Fahle M. 2004. Perceptual learning: a case for early selection. J Vis 4: 879-890.

Felleman DJ, Van Essen DC. 1991. Distributed hierarchical processing in the primate cerebral cortex. Cereb Cortex 1: $1-47$.

Frenkel MY, Bear MF. 2004. How monocular deprivation shifts ocular dominance in visual cortex of young mice. Neuron 44: 917-923.

Frenkel MY, Sawtell NB, Diogo AC, Yoon B, Neve RL, Bear MF. 2006. Instructive effect of visual experience in mouse visual cortex. Neuron 51: $339-349$.

Friston K. 2005. A theory of cortical responses. Philos Trans R Soc Lond B Biol Sci 360: $815-836$

Fu Y, Tucciarone JM, Espinosa JS, Sheng N, Darcy DP, Nicoll RA, Huang ZJ, Stryker MP. 2014. A cortical circuit for gain control by behavioral state. Cell 156: 1139-1152.

Fuster JM, Jervey JP. 1981. Inferotemporal neurons distinguish and retain behaviorally relevant features of visual stimuli. Science 212: 952-955.

Gavornik JP, Bear MF. 2014. Learned spatiotemporal sequence recognition and prediction in primary visual cortex. Nat Neurosci 17: 732-737.

Gavornik JP, Shouval HZ. 2011. A network of spiking neurons that can represent interval timing: mean field analysis. J Comput Neurosci 30: 501-513.

Gavornik JP, Shuler MG, Loewenstein Y, Bear MF, Shouval HZ. 2009. Learning reward timing in cortex through reward dependent expression of synaptic plasticity. Proc Natl Acad Sci 106: 6826-6831.

Gilbert CD, Li W. 2012. Adult visual cortical plasticity. Neuron 75: 250-264

Gordon JA, Stryker MP. 1996. Experience-dependent plasticity of binocular responses in the primary visual cortex of the mouse. J Neurosci 16: 3274-3286.

Guo K, Robertson RG, Pulgarin M, Nevado A, Panzeri S, Thiele A, Young MP. 2007. Spatio-temporal prediction and inference by V1 neurons. Eur J Neurosci 26: 1045-1054.

Hamilton RH, Pascual-Leone A. 1998. Cortical plasticity associated with Braille learning. Trends Cogn Sci 2: 168-174.

Hasan MT, Hernandez-Gonzalez S, Dogbevia G, Trevino M, Bertocchi I, Gruart A, Delgado-Garcia JM. 2013. Role of motor cortex NMDA receptors in learning-dependent synaptic plasticity of behaving mice. Nat Commun 4: 2258.

Hasselmo ME. 2006. The role of acetylcholine in learning and memory. Curr Opin Neurobiol 16: 710-715.

Hawkins J, Blakeslee S. 2004. On intelligence. Times Books, New York.

Hill SL, Wang Y, Riachi I, Schurmann F, Markram H. 2012. Statistical connectivity provides a sufficient foundation for specific functional connectivity in neocortical neural microcircuits. Proc Natl Acad Sci 109: E2885-E2894.

Hochstein S, Ahissar M. 2002. View from the top: hierarchies and reverse hierarchies in the visual system. Neuron 36: 791-804.

Hofer SB, Mrsic-Flogel TD, Bonhoeffer T, Hubener M. 2006. Lifelong learning: ocular dominance plasticity in mouse visual cortex. Curr Opin Neurobiol 16: 451-459.

Huang ZJ, Kirkwood A, Pizzorusso T, Porciatti V, Morales B, Bear MF, Maffei L, Tonegawa S. 1999. BDNF regulates the maturation of inhibition and the critical period of plasticity in mouse visual cortex. Cell 98: 739-755.

Hubel DH. 1957. Tungsten microelectrode for recording from single units. Science 125: 549-550.

Hubel DH, Wiesel TN. 1962. Receptive fields, binocular interaction and functional architecture in the cat's visual cortex. J Physiol 160: 106-154.

Hubel DH, Wiesel TN. 1968. Receptive fields and functional architecture of monkey striate cortex. J Physiol 195: 215-243.

Hubel DH, Wiesel TN. 1970. The period of susceptibility to the physiological effects of unilateral eye closure in kittens. J Physiol 206: 419-436.

Hubel DH, Wiesel TN, LeVay S. 1976. Functional architecture of area 17 in normal and monocularly deprived macaque monkeys. Cold Spring Harb Symp Quant Biol 40: 581-589.

Jehee JF, Ling S, Swisher JD, van Bergen RS, Tong F. 2012. Perceptual learning selectively refines orientation representations in early visual cortex. J Neurosci 32: 16747-16753.

Kaas JH, Krubitzer LA, Chino YM, Langston AL, Polley EH, Blair N. 1990. Reorganization of retinotopic cortical maps in adult mammals after lesions of the retina. Science 248: 229-231.

Keck T, Mrsic-Flogel TD, Vaz Afonso M, Eysel UT, Bonhoeffer T, Hubener M. 2008. Massive restructuring of neuronal circuits during functional reorganization of adult visual cortex. Nat Neurosci 11: 1162-1167.

Ko H, Hofer SB, Pichler B, Buchanan KA, Sjostrom PJ, Mrsic-Flogel TD. 2011. Functional specificity of local synaptic connections in neocortical networks. Nature 473: 87-91. 
Komura Y, Tamura R, Uwano T, Nishijo H, Kaga K, Ono T. 2001. Retrospective and prospective coding for predicted reward in the sensory thalamus. Nature 412: 546-549.

Kouh M, Poggio T. 2008. A canonical neural circuit for cortical nonlinear operations. Neural Comput 20: 1427-1451.

Krupa DJ, Wiest MC, Shuler MG, Laubach M, Nicolelis MA. 2004. Layer-specific somatosensory cortical activation during active tactile discrimination. Science 304: 1989-1992.

Le QV. 2013. Building high-level features using large scale unsupervised learning. In 2013 IEEE International Conference on Acoustics, Speech and Signal Processing (ICASSP), pp. 8595-8598. IEEE.

Lee TS, Mumford D. 2003. Hierarchical Bayesian inference in the visual cortex. J Opt Soc Am A Opt Image Sci Vis 20: 1434-1448.

Leon MI, Shadlen MN. 2003. Representation of time by neurons in the posterior parietal cortex of the macaque. Neuron 38: 317-327.

Li W. 2014. Learning to smell danger: acquired associative representation of threat in the olfactory cortex. Front Behav Neurosci 8: 98.

Li N, DiCarlo JJ. 2008. Unsupervised natural experience rapidly alters invariant object representation in visual cortex. Science 321: $1502-1507$

Matthies U, Balog J, Lehmann K. 2013. Temporally coherent visual stimuli boost ocular dominance plasticity. J Neurosci 33: 11774-11778.

Mountcastle VB. 1978. An organizing principle for cerebral function: the unit model and the distributed system. In The mindful brain: cortical organization and the group-selective theory of higher brain function (ed. Edelman GM, Mountcastle VB), p. 100. MIT Press, Cambridge.

Muckli L, Kohler A, Kriegeskorte N, Singer W. 2005. Primary visual cortex activity along the apparent-motion trace reflects illusory perception. PLoS Biol 3: e265.

Newell FN, Wallraven C, Huber S. 2004. The role of characteristic motion in object categorization. J Vis 4: 118-129.

Newton JR, Sur M. 2005. Rewiring cortex: functional plasticity of the auditory cortex during development. Plasticity and signal representation in the auditory system, pp. 127-137.

Niell CM, Stryker MP. 2008. Highly selective receptive fields in mouse visual cortex. J Neurosci 28: 7520-7536.

Ohki K, Chung S, Ch'ng YH, Kara P, Reid RC. 2005. Functional imaging with cellular resolution reveals precise micro-architecture in visual cortex. Nature 433: 597-603.

Papadopoulos GC, Parnavelas JG, Buijs RM. 1989. Light and electron microscopic immunocytochemical analysis of the noradrenaline innervation of the rat visual cortex. J Neurocytol 18: 1-10.

Patel GH, Kaplan DM, Snyder LH. 2014. Topographic organization in the brain: searching for general principles. Trends Cogn Sci 18: 351-363.

Pinto L, Goard MJ, Estandian D, Xu M, Kwan AC, Lee SH, Harrison TC, Feng G, Dan Y. 2013. Fast modulation of visual perception by basal forebrain cholinergic neurons. Nat Neurosci 16: 1857-1863.

Porciatti V, Pizzorusso T, Maffei L. 1999. The visual physiology of the wild type mouse determined with pattern VEPs. Vision Res 39: 3071-3081.

Pourtois G, Rauss KS, Vuilleumier P, Schwartz S. 2008. Effects of perceptual learning on primary visual cortex activity in humans. Vision Res 48: $55-62$.

Purves D, Lotto RB. 2011. Why we see what we do redux: a wholly empirical theory of vision. Sinauer Associates, Sunderland, MA.

Rao RP, Ballard DH. 1997. Dynamic model of visual recognition predicts neural response properties in the visual cortex. Neural Comput 9: $721-763$.

Rao RP, Ballard DH. 1999. Predictive coding in the visual cortex: a functional interpretation of some extra-classical receptive-field effects. Nat Neurosci 2: 79-87.

Riesenhuber M, Poggio T. 1999. Hierarchical models of object recognition in cortex. Nat Neurosci 2: 1019-1025.

Rokem A, Silver MA. 2013. The benefits of cholinergic enhancement during perceptual learning are long-lasting. Front Comput Neurosci 7: 66.

Sale A, De Pasquale R, Bonaccorsi J, Pietra G, Olivieri D, Berardi N, Maffei L. 2011. Visual perceptual learning induces long-term potentiation in the visual cortex. Neuroscience 172: 219-225.

Sawtell NB, Frenkel MY, Philpot BD, Nakazawa K, Tonegawa S, Bear MF. 2003. NMDA receptor-dependent ocular dominance plasticity in adult visual cortex. Neuron 38: 977-985.

Schlaggar BL, O'Leary DD. 1991. Potential of visual cortex to develop an array of functional units unique to somatosensory cortex. Science 252: $1556-1560$

Schoups A, Vogels R, Qian N, Orban G. 2001. Practising orientation identification improves orientation coding in V1 neurons. Nature 412: 549-553.

Schultz W. 1998. Predictive reward signal of dopamine neurons. J Neurophysiol 80: 1-27.

Schultz W, Dayan P, Montague PR. 1997. A neural substrate of prediction and reward. Science 275: 1593-1599.
Seitz AR, Nanez JE, Holloway SR, Koyama S, Watanabe T. 2005. Seeing what is not there shows the costs of perceptual learning. Proc Natl Acad Sci 102: $9080-9085$.

Serences JT. 2008. Value-based modulations in human visual cortex. Neuron 60: $1169-1181$.

Serre T, Oliva A, Poggio T. 2007. A feedforward architecture accounts for rapid categorization. Proc Natl Acad Sci 104: 6424-6429.

Shouval HZ, Agarwal A, Gavornik JP. 2013. Scaling of perceptual errors can predict the shape of neural tuning curves. Phys Rev Lett 110: 168102.

Shouval HZ, Hussain Shuler MG, Shouval AA, Gavornik JP. 2014. What does scalar timing tell us about neural dynamics? Front Hum Neurosci 8.

Shuler MG, Bear MF. 2006. Reward timing in the primary visual cortex. Science 311: 1606-1609.

Smith SL, Hausser M. 2010. Parallel processing of visual space by neighboring neurons in mouse visual cortex. Nat Neurosci 13: 1144-1149.

Spemann H, Mangold H. 2001. Induction of embryonic primordia by implantation of organizers from a different species. 1923. Int J Dev Biol 45: $13-38$.

Spratling MW. 2010. Predictive coding as a model of response properties in cortical area V1. I Neurosci 30: 3531-3543.

Stanisor L, van der Togt C, Pennartz CM, Roelfsema PR. 2013. A unified selection signal for attention and reward in primary visual cortex. Proc Natl Acad Sci 110: 9136-9141.

Stone JV. 1998. Object recognition using spatiotemporal signatures. Vision Res 38: 947-951.

Stone JV. 1999. Object recognition: view-specificity and motion-specificity. Vision Res 39: 4032-4044.

Sullivan MJ, Cunningham JT, Mazzella D, Allen AM, Nissen R, Renaud LP. 2003. Lesions of the diagonal band of broca enhance drinking in the rat. I Neuroendocrinol 15: 907-915.

Tavazoie S. 2013. Synaptic state matching: a dynamical architecture for predictive internal representation and feature detection. PLoS One 8: e72865.

Thomas J, Vanni-Mercier G, Dreher JC. 2013. Neural dynamics of reward probability coding: a Magnetoencephalographic study in humans. Front Neurosci 7: 214

Vogels R. 2010. Mechanisms of visual perceptual learning in macaque visual cortex. Top Cogn Sci 2: 239-250.

Vuong QC, Tarr MJ. 2004. Rotation direction affects object recognition. Vision Res 44: 1717-1730.

Wacongne C, Changeux JP, Dehaene S. 2012. A neuronal model of predictive coding accounting for the mismatch negativity. J Neurosci 32: $3665-3678$.

Wagor E, Mangini NJ, Pearlman AL. 1980. Retinotopic organization of striate and extrastriate visual cortex in the mouse. J Comp Neurol 193: $187-202$.

Wallis G. 2002. The role of object motion in forging long-term representations of objects. Vis $\operatorname{Cogn}$ 9: 233-247.

Wang X-J. 2013. The prefrontal cortex as a quintessential "cognitive-type" neural circuit. Principles of frontal lobe function, 2 nd ed. Oxford University Press, New York.

Wang Q, Burkhalter A. 2007. Area map of mouse visual cortex. J Comp Neurol 502: 339-357.

Watanabe Y, Funahashi S. 2004. Neuronal activity throughout the primate mediodorsal nucleus of the thalamus during oculomotor delayed-responses. II. Activity encoding visual versus motor signal. J Neurophysiol 92: 1756-1769.

Watanabe T, Nanez JE Sr, Koyama S, Mukai I, Liederman J, Sasaki Y. 2002. Greater plasticity in lower-level than higher-level visual motion processing in a passive perceptual learning task. Nat Neurosci 5: 1003-1009.

Weinberger NM. 2004. Specific long-term memory traces in primary auditory cortex. Nat Rev Neurosci 5: 279-290.

Weinberger N. 2011. Reconceptualizing the primary auditory cortex: learning, memory and specific plasticity. In The auditory cortex (ed. Winer JA, Schreiner CE), pp. 465-491. Springer, New York.

Wiesel TN, Hubel DH. 1963a. Effects of visual deprivation on morphology and physiology of cells in the cats lateral geniculate body. J Neurophysiol 26: $978-993$

Wiesel TN, Hubel DH. 1963b. Single-cell responses in striate cortex of kittens deprived of vision in one eye. J Neurophysiol 26: 1003-1017.

Wiesel TN, Hubel DH. 1965. Extent of recovery from the effects of visual deprivation in kittens. J Neurophysiol 28: 1060-1072.

Xu S, Jiang W, Poo MM, Dan Y. 2012. Activity recall in a visual cortical ensemble. Nat Neurosci 15: 449-455, S441-S442.

Received June 23, 2014; accepted in revised form July 29, 2014. 


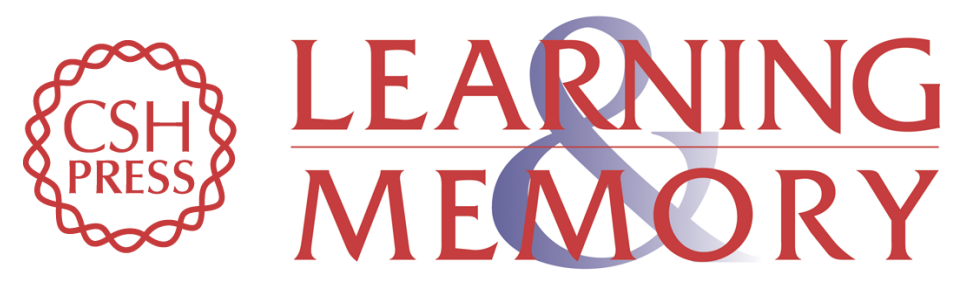

\section{Higher brain functions served by the lowly rodent primary visual cortex}

Jeffrey P. Gavornik and Mark F. Bear

Learn. Mem. 2014, 21:

Access the most recent version at doi:10.1101/lm.034355.114

References This article cites 106 articles, 25 of which can be accessed free at: http://learnmem.cshlp.org/content/21/10/527.full.html\#ref-list-1

Creative This article is distributed exclusively by Cold Spring Harbor Laboratory Press for the Commons License first 12 months after the full-issue publication date (see

http://learnmem.cshlp.org/site/misc/terms.xhtml). After 12 months, it is available under a Creative Commons License (Attribution-NonCommercial 4.0 International), as described at http://creativecommons.org/licenses/by-nc/4.0/.

Email Alerting Receive free email alerts when new articles cite this article - sign up in the box at the Service top right corner of the article or click here. 